\title{
GLOBALIZACIÓN Y MIGRACIONES TRANSFRONTERIZAS EN CENTROAMÉRICA
}

\author{
Abelardo Morales Gamboa
}

\section{Fronteras en el marco global}

S e señala con frecuencia que vivimos una nueva era, la de la globalización. Es, al decir de algunos, un cambio de época pues pocas innovaciones tecnológicas habían tenido un impacto tan grande sobre tanta gente al mismo tiempo como el que ha tenido la revolución de la información. Estamos en presencia de la construcción de una sociedad planetaria. Pero las palabras sobran para describir procesos, problemas y conflictos. De Melucci (2001) recogemos dos contribuciones que acercan nuestro tema a ese concepto.

En efecto, señala el autor que uno de los rasgos de la planetarización es la fuerte interdependencia que se produce entre todas las esferas de la realidad. Tal interdependencia tiene dos características; por una parte, "se verifica hasta los límites del planeta Tierra" y, por otra, borra las fronteras entre diversas dimensiones de la vida que habíamos aprendido a conocer de manera separada. Es una interdependencia tal que también borra las separaciones entre la naturaleza interna y la naturaleza

Abelardo Morales Gamboa, Facultad Latinoamericana de Ciencias Sociales, sede Costa Rica. externa de las diversas formas de existencia biológica y social, o bien entre la capacidad de destrucción total y la posibilidad de creación de vida con el recurso de la tecnología. El poderío del arsenal nuclear, por una parte, así como de los avances en el terreno de la genética y las neurociencias ilustran cómo las capacidades de la acción humana han desbordado el concepto de la vida con el cual nos hemos habituado a coexistir.

Por otra parte, la planetarización significa, a partir de lo antes dicho, que casi no hay espacio en el planeta que permanezca como un territorio externo a lo social. Señala el autor al respecto que lo social abarca todo el espacio disponible, no sólo el espacio físico, sino también el mental y el relacional. Es decir, las viejas delimitaciones entre lo social y lo no social parecen quedar disipadas; ya no hay mundos que conquistar y todos, y todas, transitamos en la misma nave. "...lo social depende por completo de lo social, esto es, de las relaciones, decisiones, formas de organización y poder que lo social mismo produce" (32).

No obstante, no hay tantas razones para la euforia, ni para las antiprofecías que anuncian que ya no hay futuro porque el futuro ya fue alcanzado, $y$ 
porque todo lo que se pretende esperar de él se encuentra dentro del sistema de relaciones sociales presentes. Para algunos apologistas del capitalismo, el desarrollo de una economía cada vez más interdependiente abrigaría la esperanza de una sociedad universal (Ohmae, 1990). Muy a pesar de ese universalismo monótono, la diseminación planetaria de la ley del valor y de la hegemonía tecnológica sobre las cotidianidades impone nuevos mecanismos de diferenciación social, acentúa la desigualdad y la exclusión. La historia como proceso social surgido de la persistencia de los viejos antagonismos por el acceso a medios de producción y de riqueza, que siguen concentrados y mal distribuidos, no acaba.

$\mathrm{Al}$ mismo tiempo que se configura esa sociedad planetaria, se impone cada vez con mayor veracidad que tanto en las sociedades del norte como en las del sur aparecen nuevas e implacables formas de privación económica, social y cultural en contra de mayorías y conjuntos casi absolutos. A esos antagonismos y exclusiones del modelo económico, se añaden otras exclusiones nuevas y antagonismos que habían permanecido soterrados por los viejos mecanismos de dominación política.

Se señala que dos rasgos de la mundialización son la "desterritorialización" y la abolición de fronteras por el mercado y el consumo. Pero no todos los impulsos de la planetarización provienen, como se supone, de meros actos económicos. Las migraciones laborales transfronterizas o transnacionales son uno de los movimientos que subsumen globalmente a la población; los impulsos económicos y tecnológicos operan en la base de las mismas pero de manera invertida. Fenómenos relacionados con esas dinámicas han comenzado a rebasar las categorías fijas del análisis sociológico, de la ciencia política y de las relaciones internacionales, entre ellas, los conceptos territoriales de clase y Estado, las visiones estáticas de la soberanía estatal, así como la normatividad aplicable a los actos sociales en los planos infra e interestatal.

Por lo anterior, la nueva complejidad del mundo social se presenta también como una oportunidad para la revitalización de las ciencias sociales y de la sociología en particular. La extensión de lo social a todo el espacio planetario refuerza la necesidad de dotar a las ciencias sociales de nuevos conceptos y de nuevas herramientas de investigación; pero también demanda de quienes se dedican a esos oficios académicos hacer lo posible por rescatar a la sociología de los encierros estructuralistas de antaño, y situarla en una condición más cercana a las nuevas complejidades del sistema social.

Diversos procesos sociales, con un marcado acento globalizador, acontecen en la periferia del mercado, lejos del esplendor tecnológico, y con una funesta reimposición de fronteras; la exclusión, principalmente, se manifiesta como el lado perverso de esa globalización espuria. Cabe argumentar, además, que los sujetos de esos aceleramientos y transformaciones no son, pese a las creencias tecnoburocráticas de moda, sólo ni principalmente las empresas transnacionales y entidades supranacionales, sino los individuos, ciudadanos convertidos por la magia misma de la mercantilización en simples consumidores. Barber (1995) señala que “...(los) clientes (de las corporaciones) no son ciudadanos de una nación en particular, ni miembros de un clan parroquial: ellos pertenecen a la tribu universal de los consumidores determinados por necesidades y deseos que resultan ubicuos, no por su propia naturaleza, sino por medio de la manipulación de la publicidad. Un consumidor es un consumidor" (23).

Aunque el dominio del mercado impone como regla una cierta uniformidad de los gustos y patro- 
nes de vida, en el ejercicio mismo del consumo puede producirse una especie de redención de lo íntimo, de lo propio y de lo genuino de la actividad humana, que revelan que el globalismo no sólo no comporta la homogeneidad de las operaciones económicas, sino también propicia una intersubjetividad sumamente densa y, como efecto suyo, el desarrollo de un "multiculturalismo" cada vez más expandido.

El desarrollo incesante de las innovaciones, por ejemplo, no solamente resulta de una gélida idiosincrasia del capital frente a su propia competencia, sino de una práctica cotidiana de los individuos en la búsqueda de mayores posibilidades para su subsistencia, sobre todo, entre colectivos que, en medio del aplastante efecto del espectáculo televisivo y publicitario, ingenian estrategias para satisfacer otras necesidades vitales. Si bien el desarrollo del mercado requiere de la intervención de mecanismos virtuales para la manipulación de los gustos y de las necesidades de los consumidores, ese desarrollo deja zonas extensamente descubiertas, donde las personas resuelven de maneras muy distintas sus necesidades vitales, apenas en la periferia de las relaciones mercantiles. La supervivencia es un acto densamente imaginativo y aunque sus límites sean cada vez más estrechos, esa estrechez fuerza una mayor imaginación. La imaginación no emerge asociada sólo a la creatividad del consumo, sino también al ingenio del no consumo.

En nuestros países, los ajustes macroeconómicos han constreñido los márgenes para la satisfacción de las necesidades vitales, junto a una crisis ecoambiental que merma también la disponibilidad de recursos para el crecimiento productivo y para el desarrollo social. El incremento de la vulnerabilidad frente a los riesgos ambientales recrudece la migración e incrementa el desarraigo. En el caso centroamericano, la emigración se ha convertido en una modalidad de ajuste del mercado laboral que deja en manos de los individuos y de las familias la responsabilidad de la creación de empleo.

\section{Migraciones y nuevas producciones de territorio}

También en la región, las transformaciones productivas han tenido como consecuencia, casi reiterada, nuevas manifestaciones del fenómeno migratorio. Tanto el desarrollo de la agricultura de exportación como el proceso de urbanización e industrialización han implicado la aparición de nuevas formas de salida como la atracción de otros contingentes de población. Las transformaciones más recientes, tanto las que corresponden a la dinámica de pacificación y democratización como las acontecidas en los escenarios económicos, se han encadenado a diversas transformaciones de la territorialidad social y una de sus expresiones ha sido la aparición de nuevos patrones migratorios en toda la región. A pesar de que las migraciones internas y las migraciones transfronterizas perdieron importancia relativa dentro del conjunto global de la migración en la región, ese hecho no invalida la importancia real de esas otras dos primeras formas. El principal obstáculo para descubrir el alcance y naturaleza de las migraciones intrarregionales es la ausencia de instrumentos estadísticos actualizados y de datos uniformes que capten el fenómeno y que, de igual modo, faciliten su conocimiento transversal en la región.

De modo que las migraciones también cobran importancia en el actual contexto global subregional: se han constituido en una manifestación de la transnacionalización del istmo centroamericano, por el hecho de que la emigración a países de fuera de la región, como el desplazamiento, permanente o tem- 
poral, entre países al interior de la zona, revelan las aristas más novedosas de un proceso de transnacionalización de la fuerza laboral como también de los mecanismos de reproducción y sobrevivencia social. Para los países centroamericanos que dependen altamente de la emigración, sea ésta a los Estados Unidos o a territorios vecinos, el sur de México, Belice o Costa Rica, ciertos balances macroeconómicos y la mejor política social dependen de la estabilidad de un flujo constante de remesas familiares desde el exterior. Ese fenómeno tan propio de la globalización es hoy en día resultante de crecientes asimetrías entre países y entre territorios. En tanto, esa nueva forma de dependencia externa se revela como estratégica, puede decrecer el interés por el desarrollo social y productivo de las zonas expulsoras $\mathrm{y}$, de esa forma, tales territorios quedan conectados a los circuitos de la transnacionalización mediante la conexión de su fuerza de trabajo con mercados laborales en el exterior.

Pero las implicaciones de tal transnacionalización no son sólo económicas ni laborales. Otro ámbito cambiante es la diseminación de nuevas instituciones y urdimbres socioterritoriales. García Canclini (1991), a propósito, identificaba un fenómeno dual de "desterritorialización y reterritorialización" de la cultura, coherente con dos procesos: "la pérdida de la relación natural de la cultura con los territorios geográficos y sociales, $\mathrm{y}$, al mismo tiempo, ciertas relocalizaciones territoriales relativas, parciales, de las viejas y nuevas producciones simbólicas" (288). La expresión de esa desterritorialización se observa en la principal zona de migraciones del continente y tal vez del mundo, la frontera entre México y Estados Unidos, y está contenida en un movimiento intercultural de trabajadores y trabajadoras desempleadas, campesinos e indígenas desarraigados, que debieron salir de sus tierras para sobrevivir.
Sin embargo, en la región objeto de este análisis, ese fenómeno manifiesta características que difieren de ese caso no sólo en sus rasgos más importantes sino también por una cuestión de escala. Las fronteras en el istmo centroamericano dividen a sociedades más homogéneas que lo que resultan ser entre sí la mexicana y la estadounidense; aparte de que en términos espaciales las migraciones dentro del área involucran zonas más reducidas. Pero a pesar de las diferencias de escala y una homogeneidad relativamente mayor, en Centroamérica también tienen importancia las transformaciones socioterritoriales asociadas a la migración, también como procesos de "reterritorialización" de esos sitios.

La reterritorialización se manifiesta como una oposición interesante entre la producción de lugares y la de no lugares (Augé, 1996). ${ }^{1}$ La diseminación de las poblaciones móviles, entre uno de los tantos efectos de las transformaciones territoriales y otros cambios estructurales, produce transformaciones espaciales también diversas; la producción de "no lugares" en una escala micro sería la medida de la época, son los espacios consagrados a la individualidad solitaria del consumo, a las actividades provisionales y ubicuas; son espacios del pasaje y dedicados al desplazamiento que cobran importancia por el peso de la comunicación y el transporte en el desarrollo de la actividad económica, en la difusión simbólica y en los movimientos poblacionales a escala global.

Consagrados como sitios de tránsito y pasaje, las fronteras evidencian la falsa polaridad entre los lugares y los no lugares; posmodernas por excelencia, las fronteras no pierden, con el impacto de lo global y lo posmoderno, su historicidad, su carácter de identidad y la importancia de las prácticas sociales allí presentes. Más bien, el transnacionalismo produce una nueva práctica de las fronteras, cuyo efecto re- 
sultante es una nueva producción de lugares, y cuya manifestación más específica es la "transfrontericidad" como sitio de esa posmodernidad. A diferencia de otros sitios, lo particular de lo transfronterizo es el espacio de cruce, de redes de medios de transporte, de tránsito tanto formal como informal, de comercio y de redes sociales diversas; también es el cruce entre lo tradicional y lo posmoderno, tanto de ancestrales intercambios familiares y comunitarios, como de tecnologías y turismo; en consecuencia, las fronteras son el cruce posmoderno entre los lugares y los no lugares.

El carácter dual de la territorialidad migratoria se manifiesta en la imagen del sujeto migrante. Lejos estaríamos de considerar a los migrantes como habitantes de los no lugares; lo propio del migrante es su capacidad de movimiento entre uno y otro espacio pero, además de ello, su capacidad de construir lugares dentro de espacios antropológicos amplios; espacios sociales transfronterizos o transnacionales. La identidad del migrante aparece asociada entonces tanto a un imaginario como a una realidad; aunque la realidad del migrante no resulta ser necesariamente el extremo opuesto de la realidad de su imagen; así como tampoco los no lugares serían el opuesto del lugar. La construcción de un imaginario social en el entorno de la migración forma parte del proceso de producción del acto migratorio que es un proceso de construcción material y simbólica. La consecuencia es a veces, inclusive, la fabricación de imágenes diversas y hasta opuestas del sujeto migrante, que es un sujeto histórico, con una identidad y resultado de relaciones sociales específicas. El desafío para las ciencias sociales de este nuevo fenómeno ha sido precisamente el de intentar dar cuenta de aquellos procesos productivos alrededor de los cuales se gestan las migraciones, pero además entender ese proceso como la construcción social de las dinámi- cas migratorias, y como fenómeno social es también una construcción cultural.

La dinámica de la migración y el carácter de los movimientos, experiencias personales y colectivas, así como las diversas realidades del arraigo y desarraigo, inciden sobre la conformación de una multiplicidad de características del sujeto emigrante o inmigrante. El perfil de ese sujeto, a su vez, cambia de conformidad con otras variables relacionadas con aspectos sociodemográficos, económicos y culturales; por ejemplo, las de género, edad y procedencia social son de una gran importancia. El sujeto migrante en razón de su ubicuidad y movimiento tiene un lugar en el espacio social, un papel en la construcción de la historia social y le pertenece uno o múltiples trozos de la identidad social que va siendo labrado en los marcos de la época de la información. ${ }^{2}$

En consecuencia, la construcción de ese imaginario social de la migración está sujeto a una producción simbólica de lugares. Muchos de los actos de la migración están motivados por un imaginario colectivo de oportunidades, que produce la reinvención colectiva y constante de la "tierra prometida". Pero también las vivencias colectivas tienen entre una de sus manifestaciones la producción de un "nosotros" en tierra extraña, un nosotros que retorna a los lugares de origen como un capital cultural acumulado a punta de experiencias, frustraciones, alegrías y esperanzas. En otro extremo, la representación estereotipada produce una burda diferenciación del migrante frente a los otros, no migrantes, habitantes de los espacios que les hace responsables de la mayoría de los males que allí se padecen. ${ }^{3}$ Por lo tanto, la construcción simbólica de la migración es un terreno de antagonismos entre estructuras simbólicas adversas y por lo tanto hacen de la migración un terreno también de conflicto cultural, 
muy propio de las nuevas contradicciones del sistema social.

La desterritorialización, como señaláramos, es un fenómeno originado en la pérdida de referentes de los sitios de origen de bienes y personas, y que resulta de la ubicuidad de procesos productivos, la velocidad de la información y la volatilidad del consumo. Ese fenómeno es congruente entonces con la proliferación de no lugares. Mientras tanto la emigración de los pobres como el desplazamiento causado por la violencia dan forma a otra desterritorialización más perversa y cruel; un desprendimiento que resulta del despojo y del desarraigo. Esa desterritorialización manifiesta el lado perverso del posmodernismo, y se instituye a partir del rompimiento de núcleos familiares, la desintegración de núcleos vitales de la vida comunitaria y el desarraigo colectivo de masas de población, privadas éstas de la posibilidad de llenar sus necesidades de sustento en sus países de origen. La pérdida del territorio es una situación que no se vive, simplemente se padece. Pero traducir ese padecimiento como desgracia a una injusticia que no se debe tolerar, obliga a una rebelión política que parece no estar todavía al alcance de los movimientos sociales comprometidos con los sujetos migrantes. Pero el derecho a tener un lugar, así como el derecho a ser de algún lugar, es un desafío político que tarde o temprano se encarará dentro de las nuevas formas de reivindicación.

La emigración/inmigración en su configuración territorial imprime a familias y comunidades un carácter transversal. La cotidianidad de la interacción familiar y la vida de pueblos cada vez más numerosos comienzan a depender de la generación de ingresos en uno y otro país. Pero esa dinámica tiene otro trasfondo: la actividad productiva, es decir, la dinámica del capital también muestra su dependencia de la existencia de contin- gentes trabajadores superiores a los disponibles en el territorio económico inmediato. La contradicción capital-trabajo también asume sus propias expresiones en este contexto; pues la problemática social de la migración laboral evidencia un desplazamiento de las contradicciones sociales y formas de exclusión desde los territorios nacionales, propios del modelo socioeconómico previo, a la arena regional y transnacional. De la misma forma en que emergen circuitos económicos extendidos por el espacio regional, reconfigurando aquella vieja regionalidad sujeta a la agroexportación y al fallido intento del mercado común, también la fuerza de trabajo se extiende regional y extrarregionalmente para alcanzar condiciones de mayor reproducción social. Junto a esa regionalización y transnacionalización, se expanden también las formas de exclusión socioeconómica, los mecanismos de explotación de esa fuerza de trabajo, agravadas y legitimadas con otras expresiones de exclusión social y cultural.

Si bien el fenómeno migratorio tiene ese fundamento económico último, también origina un sinnúmero de otras expresiones sociales que se manifiestan en nuevos comportamientos y formas de articulación, las que suministran a colectivos familiares y comunitarios nuevas formas de participación en la construcción de espacios transfronterizos. La formación de actores sociales en el contexto de la migración no se deriva de forma exclusiva de la intervención de mecanismos de diferenciación de carácter distributivo, sino también de la creciente importancia de otros rasgos de diferenciación relacionados con la identidad y la conformación de colectividades simbólicas.

El componente transnacionalizado o transfronterizo de la vida social, por la vía de las migraciones, ha dejado ser un hecho circunstancial o un fenómeno al margen de las actividades vitales de las distin- 
tas sociedades involucradas, no sólo de una o pocas de ellas. Tanto depende la sociedad de origen de fuentes de empleo, recursos y otros medios de vida obtenidos por una parte de su población en la sociedad o sociedades de destino de la emigración, como dependen estas últimas de la primera para la provisión de recursos laborales de los cuales no disponen. Pero en el fondo de esa interdependencia también se construye un conjunto de redes y dinámicas transversales que tienen un efecto social sobre sus espacios territoriales. Si bien es uno de los rasgos más sobresalientes en la construcción social de una nueva regionalidad centroamericana, junto a ella se visibiliza también el ensamblaje de nuevas formas de interacción entre sociedades, puestas más en evidencia por la transnacionalización y la transformación regional de los mercados laborales. ${ }^{4}$

Un plano de esa regionalización se manifiesta en una serie de tendencias hacia la diferenciación territorial entre regiones, como un fenómeno asociado a la lógica de intervención territorial de las empresas. Esas tendencias llevan a reforzar una dinámica de competencia entre territorios, bajo las mismas normas de la competencia libre de mercados, tanto por la asignación de recursos, como por otras demandas particulares como cuotas de mercado, atracción de tecnologías, incentivos, infraestructura, etcétera. Con la intensificación de procesos económicos y sociales, los procesos de regionalización se vuelven más complejos, pues están sometidos a mecanismos de diferenciación territorial mucho más intensos y condicionados, también, por el fortalecimiento de tendencias económicas y sociales globalizantes.

Entre los procesos asociados a la globalización que están teniendo un mayor impacto en la configuración de nuevas regiones en Centroamérica, se pueden considerar al menos cuatro: a) la industria maquiladora, b) la producción de agroexportación tradicional, c) la producción de enclave, que sigue girando predominantemente en torno al banano, $\mathrm{y}$ d) las migraciones internacionales. Aún no se cuenta con un conocimiento avanzado de las implicaciones de esos procesos sobre la escala de construcción regional en Centroamérica, pero constituye un campo de trabajo que puede revelar buena cantidad de novedades.

Pese a la creencia de que ese regionalismo, influido por ideas neoliberales, y resultante del emplazamiento de actividades globalizadas, propicia una mayor autonomía regional, más bien podría existir el riesgo de incentivar una competencia interregional ruinosa, que alimenta una serie de desequilibrios que después exigirían la intervención estatal para corregir sus consecuencias negativas. ${ }^{5}$ Un caso evidente se ha observado, por ejemplo, en los variantes ciclos de las inversiones en la plantación bananera de Costa Rica durante las últimas dos décadas. Su retiro de la zona sur del país y posterior incentivo en la zona noratlántica evidencia los trazos de esa competencia territorial perniciosa para el desarrollo integral de economías tan vulnerables como las centroamericanas. Puede decirse lo mismo en relación con las consecuencias regionales de la desaparición del cultivo del algodón en los departamentos del occidente de Nicaragua, y la crisis de rubros de agroexportación y la ganadería en otras regiones nicaragüenses, frente a las oportunidades que comienzan a adquirir otros territorios en países vecinos como resultado de la ampliación de la economía transnacional.

La construcción regional, en otra perspectiva, imagina la ampliación de un tejido socioproductivo que resulta de una "estructura política regional fundada desde abajo, partiendo de la generación de riqueza regional, utilizando estructuras de producción poco productivas pero crecientes, y de entrelazar las tradiciones histórico-económicas y cultural-económicas y sobre todo el personal calificado" (Arndt, 1995: 121). 
Pero aparte de la dimensión socioproductiva, los componentes culturales, de género y socio-afectivos conforman una argamasa ecosocial, compuesta por redes, símbolos, objetos e interacciones, sobre cuyo soporte se tejen nuevas identidades sociales y constituyen el germen de nuevas conformaciones socioterritoriales.

Por otra parte, la transnacionalización de diversas actividades productivas en zonas de frontera agrícola se ha ido operando en Centroamérica, casi, simultáneamente, junto a un proceso de formación de "regiones transfronterizas" o territorios binacionales que integran espacios territoriales adyacentes en varios países dentro de un sistema regular de relaciones. La frontera opera en ese espacio como la variable de diferenciación con otras zonas o territorios (Morales, 1987a). Tras ese fenómeno se revitalizan las redes y canales de conexión tanto formales como informales, que ejercen presión sobre las políticas y dinámicas institucionales en el manejo de los problemas fronterizos por parte de los Estados nacionales o de los poderes locales. Tales redes y sistemas de conexión tienden a organizarse a partir de ciertos ejes transversales que se pueden identificar a partir del flujo de relaciones entre dos o más centros geográficos ubicados a ambos lados de la franja fronteriza.

En la conformación de los tejidos socioterritoriales, las migraciones están teniendo una enorme influencia. Los mecanismos articuladores de tales tejidos son los vínculos que los sujetos migrantes dejan establecidos en cada sitio. Las prácticas migratorias y la estampa de las percepciones y el imaginario común desarrollado a partir de tales experiencias crean y refuerzan nuevas expresiones de la espacialidad, que interesan en este análisis en dos dimensiones: la primera, correspondiente a lo que denominaríamos la dimensión socioterritorial y, la segunda, la dimensión interterritorial.
La incorporación del tema de la territorialidad, como referente analítico de las migraciones, permite, además, dilucidar dos conceptos fundamentales. La dimensión socioterritorial está constituida, básicamente, por el emplazamiento, en el espacio territorial, de prácticas, dinámicas y relaciones sociales que resultan, o sirven de soporte y trasfondo, a los movimientos ligados a la emigración/inmigración. Es decir, se trata de un nivel de las relaciones entre actores sociales y espacio, como proceso que conduce a la conformación de diversas situaciones territoriales. La práctica migratoria tiene la particularidad de que el espacio territorial pasa a ser incorporado dentro de las estrategias de sobrevivencia asociadas a dicha práctica.

Entre tanto, el fenómeno de la interterritorialidad abarca un proceso más específico que deviene de la amalgama de contactos y relaciones entre comunidades y regiones: es decir, está referida a un marco situacional diferente, pero no del todo ajeno a la socioterritorialidad, pues se conforma a partir de diversas vinculaciones, interacciones y, en general, de variadas formas de segregación o acoplamiento entre territorios contiguos o discontinuos. Tales territorios pueden corresponder, según cada situación, a una misma unidad espacial, como por ejemplo un territorio administrativo, o bien a unidades de distinto tamaño o configuración, en el ámbito nacional o binacional.

\section{El fenómeno de las migraciones en la región y su contexto}

La movilidad de las poblaciones de la región entre un territorio y otro registra una serie de cambios en sus modalidades. Principalmente, en el último decenio, las migraciones han estado caracterizadas por sus aspectos particularmente laborales. Esto último formula un cambio respecto de las características 
del fenómeno en los decenios anteriores, en específico, en los países que estuvieron afectados por conflictos armados.

Esas particularidades laborales coinciden con el hecho de que la migración parece haberse convertido durante la década de los noventa y principios de la siguiente, en uno de los principales efectos del ajuste estructural sobre los mercados de trabajo de la región centroamericana y de la República Dominicana.

Otro nuevo atributo de ese fenómeno, respecto de los periodos anteriores, es el repunte de los flujos intrarregionales dentro del conjunto de los movimientos migratorios. Mientras que en las décadas de los setenta y de los ochenta crecieron las migraciones extrarregionales, principalmente hacia los Estados Unidos, los desplazamientos entre los países de la región han vuelto a recuperar importancia durante la década siguiente. Aunque como fenómeno se extiende por toda la región, se concentra en unos cuantos flujos transfronterizos entre países vecinos: Guatemala-Belice; Guatemala-México; Nicaragua-Costa Rica y Haití-República Dominicana.

Si bien el tema ha comenzado a ser objeto de atención en el análisis social y en círculos políticos, todavía se desconoce mucho sobre la problemática específica de los movimientos de población y más aún sobre sus implicaciones en materia de salud. Una de las mayores dificultades reside en que los sistemas y los instrumentos de registro, de los cuales disponen los países, resultan insuficientes para captar la intensa movilidad de personas y las características de ésta, al interior de cada territorio nacional como entre las fronteras comunes. Debido a que una buena proporción de esos movimientos no se documentan, la información estadística presenta importantes subregistros. Aparte de ello, estas y otras carencias de información propician el desconocimiento casi general sobre las particularidades y las situaciones que experimentan los sujetos involucrados en tales desplazamientos.

Los movimientos de población se han gestado muy antiguamente entre los países de la región, por lo tanto existe un conjunto de viejos patrones migratorios como de otros fenómenos nuevos. Sus causas han sido tanto económicas como políticas; unos y otros factores han adquirido importancia en diferentes momentos como muestra fehaciente de que los acontecimientos históricos han estado cargados de vicisitudes económicas y de una recurrente inestabilidad política. Ambas situaciones han lanzado su carga de vulnerabilidad sobre amplios colectivos que se han visto forzados a abandonar sus comunidades de origen y sus países, ya sea en búsqueda de la protección para sus vidas o de su supervivencia económica.

En cualquiera de las circunstancias, los movimientos migratorios han contribuido a una redistribución demográfica dentro de los países y entre la región, de la cual se desconocen también muchos elementos, aunque se presume que en las últimas décadas se ha acelerado y ha adquirido nuevos rasgos.

En la actualidad, las corrientes de migración tienen las siguientes expresiones:

\section{Migraciones internas}

Son desplazamientos de personas que ocurren entre una región y otra de un mismo país. Sus causas han sido las crisis en la producción agrícola, la mala distribución de la propiedad rural, la apertura de frentes pioneros de colonización agrícola, la demanda de trabajadores estacionales para la producción de agroexportación y los procesos de urbanización.

En el periodo reciente las migraciones internas están presentes en todos los países de la región. 
Sin embargo, su impacto es preponderante en Guatemala, Honduras, Nicaragua y República Dominicana.

En los demás países el fenómeno no carece de importancia, pero al parecer tiene una incidencia menor que en los otros escenarios. En todos los países la movilidad interna de personas está constituida por: (1) las migraciones de trabajadores temporales hacia la agricultura; ${ }^{6}(2)$ la migración hacia la frontera agrícola (Guatemala y Nicaragua); (3) migración hacia las ciudades.

\section{Migraciones transfronterizas}

Éstas son migraciones entre países limítrofes con dos destinos: a) localidades adyacentes a las fronteras y zonas de plantación; b) las ciudades.

Las zonas fronterizas adquieren una enorme importancia para la filtración de movimientos de personas, pues es allí donde se concentra la interacción migratoria que compromete especialmente a países vecinos de la región. En efecto, tal y como fue señalado anteriormente, las poblaciones móviles y la interacción migratoria se concentran en cuatro regiones fronterizas, principalmente: GuatemalaBelice; Guatemala-México; Nicaragua-Costa Rica y Haití-República Dominicana.

Algunas corrientes de migración interna son a su vez alimentadas por la inmigración desde el exterior, debido a que los trabajadores extranjeros, al seguir la trayectoria de los ciclos de cosecha y de los demás empleos, se convierten a su vez en migrantes internos en los países receptores.

\section{Migraciones extrarregionales}

Este fenómeno consiste de los movimientos de migrantes desde los países de la región hacia otras regiones del mundo. De ese fenómeno se conocen las emigraciones de nacionales de los distintos países centroamericanos y de la República Dominicana hacia Estados Unidos y Canadá. También incluye flujos de emigrantes hacia otros continentes, donde la emigración hacia Europa ha adquirido importancia especial para los nacionales de la República Dominicana.

\section{Las transmigraciones}

Debido a su particular posición en el hemisferio y su cercanía con los Estados Unidos, los países centroamericanos también sirven como puente de un importante flujo de personas que emigraron desde otros países de la misma región, de otras regiones del hemisferio o bien desde otros continentes. Lo particular de esos movimientos es que se organizan con la pretensión de llegar a los Estados Unidos. Una gran proporción de estos inmigrantes carecen de documentos legales para realizar su viaje a ese país; son víctimas de redes de traficantes y en incontables oportunidades ven frustradas sus pretensiones de llegar a su destino final. Por esa razón, una gran cantidad de esos inmigrantes pueden quedarse rezagados en la región, lejos de sus países de origen.

En el siguiente apartado se explica la forma en que estos cuatro tipos de migración se manifiestan entre los nuevos patrones migratorios en la región centroamericana y en República Dominicana.

\section{Principales elementos en los nuevos patrones migratorios (1990 - 2002)}

Los principales cambios en el patrón migratorio que había predominado hasta 1970 fueron los siguientes: (1) la magnitud de los flujos, (2) las causas de la migración, (3) la composición social de los grupos, 
(4) la relación entre lugares de origen y lugares de destino. Pero el fenómeno completamente novedoso fue el incremento de las migraciones extrarregionales que, principalmente en Centroamérica, desplazaron en importancia a las migraciones entre los países vecinos.

En efecto, en los países del Istmo, las migraciones entre vecinos representó entre 50 y 60\% de los movimientos hasta la década de los setenta. ${ }^{7} \mathrm{La}$ emigración extrarregional había sido equivalente a $40 \%$ de los movimientos registrados en la región. Entre los ochenta y los noventa esa relación varió significativamente; la emigración extrarregional pasó de 48.8 a $92.5 \%$, y las migraciones intrarregionales o transfronterizas ${ }^{8}$ se redujeron a $7.5 \%$ del total de los desplazamientos (CELADE, 1998). Pero ese cambio no fue el resultado de una disminución real de los flujos transfronterizos, ni del conjunto de la migración dentro de la región, sino de un incremento acelerado del otro fenómeno. Mientras tanto en República Dominicana la emigración hacia Estados Unidos y Europa creció en importancia durante esos mismos periodos; no obstante, también ese país se mantuvo como receptor de inmigrantes desde Haití. Aunque no se dispone de cifras confiables, esa inmigración creció durante las décadas de los ochenta y los noventa como consecuencia de la crisis económica, así como por la inestabilidad política en Haití.

Los flujos más importantes de las migraciones transfronterizas, durante el periodo en Centroamérica, fueron los éxodos por razones laborales, que sustituyeron en importancia a los desplazamientos por causas políticas de los años ochenta. ${ }^{9}$ En el caso de Haití, los elementos laborales y económicos se entrelazan en la formación de los factores precipitantes de la emigración hacia República Dominicana. ${ }^{10} \mathrm{La}$ información disponible (estudios regionales, datos censales y encuestas de hogares) tampoco facilita una caracterización de dichos flujos, ni se pueden establecer diferencias concretas entre los diversos fenómenos y sobre su evolución a lo largo de la década. ${ }^{11}$

Por otra parte, los eventos migratorios tienen una prevalencia diferenciada entre países y entre regiones diversas dentro de cada país. En el caso centroamericano la llegada de inmigrantes desde países vecinos representó en promedio durante los noventa alrededor de $68 \%$ del total de la población extranjera registrada en la región.

Si bien la emigración extrarregional revela una problemática compleja, las migraciones transfronterizas pueden a su vez poner al descubierto problemáticas igualmente críticas en tanto que involucran a conjuntos de población vulnerable, que son privados de un conjunto de derechos, y que se mueven en escenarios donde prácticamente ha habido poca respuesta desde las instituciones estatales y desde otras instituciones sociales a sus necesidades.

La información disponible de bases estadísticas, con excepción del caso de Costa Rica, se centra en la primera mitad de los noventa. En ese momento, como resultado del retorno de refugiados y el incremento de la emigración extrarregional, descendía el peso relativo de las migraciones transfronterizas. Sin embargo, no se cuenta con bases de información para identificar tendencias posteriores, que corresponden justamente con la segunda mitad de esa década, cuando se presume que volvieron a cobrar importancia las migraciones entre fronteras vecinas. En ese período la movilidad de personas puede haber sido impactada por dos situaciones: el efecto de los programas de ajuste estructural tanto en Centroamérica como en el Caribe y los daños causados por eventos climáticos (sequías, huracanes, inundaciones) en toda la región, y los terremotos de El Salvador en 2001. La migración haitiana también 
ha tenido como detonante una situación política altamente frágil e inestable en el transcurso de la última década.

Datos desagregados y la observación de campo hacen presumir que las migraciones transfronterizas volvieron a adquirir importancia, a partir de la segunda mitad de los noventa, dentro del contexto general de la migración. Los casos más evidentes son las migraciones de nicaragüenses hacia Costa Rica y de los haitianos a República Dominicana. En la primera situación el fenómeno creció a lo largo de la década, pero presentó sus picos más elevados en la segunda mitad. De acuerdo con datos del último censo de población de 2000, en Costa Rica había 226374 nicaragüenses residiendo habitualmente en el país, otro tanto no calculado estaría conformado por población, también nacida en Nicaragua, que se mueve dentro ciclos temporales cortos o, bien, que no fue captada en la medición por no estar asentada en residencias habituales. Según estudios elaborados por expertos del Instituto Nicaragüense de Estadística y Censos de Nicaragua (INEC), 78\% de los nicaragüenses que emigraron hacia Costa Rica salieron después de 1993 (Rosales y otros, 2001).

Por otra parte, las anteriores tipologías migratorias comienzan a perder vigencia: ${ }^{12}$ hasta comienzos de la década, El Salvador, Guatemala y Nicaragua expulsaban importantes flujos de migración política y refugiados; en el último decenio, esos tres países, junto con Honduras, despedían población hacia los Estados Unidos; también esos cuatro países lo hacían con población indocumentada hacia otros países de la región. La población guatemalteca y salvadoreña hacia Belice y los nicaragüenses hacia Costa Rica.

Sin que se conozca toda la magnitud del fenómeno, Guatemala se convirtió también en país receptor de trabajadores salvadoreños, hondureños y nicaragüenses en las agroindustrias ubicadas en la costa del Pacífico, pero también de cientos de indocumentados centroamericanos que eran rechazados desde México. En ese país se registra una importante incorporación de trabajadores agrícolas "temporeros" centroamericanos (principalmente hondureños, salvadoreños y nicaragüenses) en los cultivos de banano, melón, caña y café ubicados en los departamentos de Izabal, Zacapa, Escuintla y Santa Rosa, respectivamente. La presencia de inmigrantes centroamericanos es perceptible también en algunas ciudades, donde se confunden con los miles de trabajadores locales dedicados al sector informal.

República Dominicana tiene también la doble característica de ser país expulsor y país receptor de migrantes. De acuerdo con el censo de Estados Unidos de 2000, los dominicanos eran el cuarto grupo en importancia de la comunidad hispanoparlante, después de los mexicanos, los puertorriqueños y los cubanos.

Aparte de ese cambio en los flujos migratorios, los países centroamericanos se han constituido también en lugares de recepción de inmigrantes llegados desde otras regiones, e inclusive desde otros continentes, que han utilizado a Centroamérica y a las Antillas como vía en sus intentos de llegar a los Estados Unidos. Se han detectado grupos de inmigrantes procedentes de diversos países de América del Sur, así como de Asia y África. ${ }^{13}$ Panamá es la puerta de ingreso de la mayor parte de los inmigrantes extrarregionales; $90 \%$ de inmigrantes indocumentados retenidos en 1997 procedía de Colombia, Cuba, Ecuador, Haití, Perú y República Dominicana; $10 \%$ restante llegaba desde China, India, Nigeria, Liberia y Ghana. La mayoría son adultos, entre los 18 y 40 años, del sexo masculino; $12 \%$ eran mujeres; y $8 \%$ menores de edad. Sin embargo, las autoridades de migración de Panamá no disponen de información que permita caracterizar los per- 
files sociodemográficos de los inmigrantes, tanto de los documentados como de los indocumentados.

\section{Perfiles sociodemográficos de la migración transfronteriza en Centroamérica}

Una de las preocupaciones en el análisis de los nuevos fenómenos migratorios dentro de la región es el conocimiento de las características sociodemográficas de los sujetos involucrados en esa dinámica. El alto volumen de indocumentación que se supone predomina dentro de esas corrientes, es uno de los principales obstáculos para discernir adecuadamente la composición social de los grupos a partir de las variables demográficas. Para la elaboración de este informe no se contó con información desagregada sobre los perfiles sociodemográficos de los inmigrantes haitianos en República Dominicana, no obstante se proporcionarán algunos datos al respecto a manera de ilustración.

Los instrumentos de registro no han sido diseñados con el fin de captar este tipo de información. Los únicos instrumentos que permiten disponer de información sociodemográfica estandarizada son los censos y las encuestas de hogares, con la limitación que tienen éstos en términos de subregistro. La carencia de análisis específicos también produce otro problema: la nueva migración de tipo económico se entremezcla con los procesos de retorno de comunidades y grupos involucrados en los desplazamientos transfronterizos en las décadas anteriores a los noventa. Por esa misma razón, aunque el movimiento de retorno supuestamente hace disminuir el peso relativo de la migración intrarregional, también los eventos vinculados a ésta involucran el traslado de personas, sobre todo niños y jóvenes, que han nacido en los países vecinos pero que también son hijos de padres que se han repatriado después de haber vivido exiliados, refugiados o simplemente desplazados de manera forzosa.

Por otra parte, a partir de la información disponible, tanto de tipo estadístico, como otro tipo de observaciones, es pertinente volver a enfatizar el peso del componente laboral como la principal característica que adquiere el fenómeno en la década de los noventa. Si bien persistían remanentes de población que se había desplazado por razones políticas, el cambio en los antiguos escenarios de conflicto y el impacto de los programas de ajuste y de la crisis incrementaron el peso de las causas económicas en la activación de los circuitos migratorios intercentroamericanos a partir de la década de los noventa.

Una primera característica tiene que ver con la edad de los migrantes. Ese rasgo permite ubicar a

\section{Cuadro 1}

Población inmigrante censada en países centroamericanos según algunos grupos de edades (en porcentajes)

\begin{tabular}{|c|r|r|r|r|}
\hline $\begin{array}{c}\text { Grupos de edad } \\
\text { en años }\end{array}$ & \multicolumn{4}{|c|}{ País de residencia } \\
\cline { 2 - 5 } ( Costa Rica $^{(1)}$ & E1 Salvador & Guatemala & Nicaragua \\
\hline 10 a 19 & 13.4 & 28.8 & 6.4 & 43.3 \\
\hline 20 a 49 & 16.1 & 16.2 & 16.6 & 17.8 \\
\hline 50 y más & 59.3 & 39.5 & 56.7 & 27.4 \\
\hline
\end{tabular}

(1)Datos del censo 2000, información preliminar. 
ese grupo de población en edad plenamente productiva. De esa manera, es posible derivar de allí algunos supuestos relacionados con la edad. En efecto, este es un fenómeno que está involucrando principalmente, aunque no de forma exclusiva, a población adulta. Los datos para el caso costarricense son claros al respecto; allí, casi 60\% de los nacidos en el resto de Centroamérica se coloca en edades entre los 20 y los 49 años. En ese país, ese dato está fuertemente influido por el peso que tienen los nicaragüenses. Una situación similar se observa en el caso de Guatemala, donde también más de la mitad de la población nacida en el resto de la región pertenece a ese mismo rango de edad. Con base en este dato, se podría suponer que en su mayor parte la emigración transfronteriza está constituida por adultos que se desplazan individualmente; el peso de la migración de grupos constituidos por familias nucleares reviste menos importancia. En República Dominicana, las plantaciones de caña de azúcar atraen principales a unos 30000 varones adultos jóvenes (20-30 años) durante la época de la zafra que dura aproximadamente seis meses. Las mujeres pueden representar cerca de $10 \%$ de esos inmigrantes (ver cuadro 1).

De lo anterior se derivan otras dos observaciones: por una parte, al estar motivada por razones económicas, la migración involucra principalmente a personas en edad de trabajar, por eso mismo es que también hay un importante segmento de adolescentes y jóvenes, quienes muy posiblemente se integran en ella como parte de sus primeras incursiones en el mercado laboral o como acompañantes de otros parientes. Esto forma parte de las estrategias dirigidas a intensificar el uso de la fuerza de trabajo del conjunto de la familia. Tanto por razones del costo económico del traslado como por las dificultades para disponer de viviendas $\mathrm{y}$ de adecuados lugares de residencia para la familia, todos aquellos que no están en condiciones de incorporarse al trabajo, permanecen en los lugares de origen. Esa decisión también está relacionada con una división, entre países emisores y receptores, de los costos y los beneficios de la migración y de la reproducción de un contingente de población, que de persistir las condiciones que lo propician y lo permitan, tarde o temprano, se incorporarán a las mareas migratorias. También la división intrafamiliar provoca una nueva problemática relacionada con la seguridad de los miembros del hogar que son más vulnerables.

Es necesario además prestar atención adicional a dos situaciones. Se trata efectivamente del peso que tiene la población infantil en Nicaragua y El Salvador; en el primer país conformaban más de $40 \%$, mientras que en El Salvador, casi 30\% de los inmigrantes captados, respectivamente. Se trata en hipótesis de que buena parte de ese grupo estaría constituido por los hijos de nicaragüenses y salvadoreños, quienes abandonaron sus países durante los años de conflicto armado y retornaron posteriormente dentro de los programas de repatriación. Desde otra perspectiva no habría explicación para esa situación, en especial en dos países que históricamente no han sido receptores sino expulsores de población. Esa misma situación ejemplifica la conexión que se produce, principalmente durante los primeros años de la década, entre las migraciones laborales y el retorno de refugiados y desplazados políticos por el conflicto armado, después del retorno de la democracia.

Los varones haitianos que emigran hacia República Dominicana muchas veces se hacen acompañar de sus familias, por lo que la presencia de niños y niñas migrantes también es un fenómeno recurrente. Aparte de ello, diversas organizaciones 
señalan que en ese país los niños nacidos de padres haitianos no siempre son reconocidos como nacionales.

La segunda cuestión que permite ver la información censal es la elevada presencia de mujeres dentro del conjunto de la población nacida en algún país centroamericano, pero residente en otro país de la región.

Esa feminización de las migraciones es una característica reciente de la emigración extrarregional, por lo que su manifestación en la dimensión transfronteriza es congruente con la constitución de los nuevos patrones migratorios. Dada la importancia de esa participación de las mujeres, es pertinente señalar que si bien el perfil laboral de ese universo es sumamente relevante, ya no involucra solamente, ni mayoritaria ni exclusivamente, a individuos del sexo masculino, ni tampoco a jornaleros agrícolas. Como podrá observarse más adelante, se trata de un espectro social más amplio y diverso, y eso mismo cobra importancia a la hora de relacionar este fenómeno con la dinámica laboral.
De conformidad con el cuadro 2, a partir de información censal, la participación femenina en el desplazamiento migratorio se coloca en promedio por encima de la presencia de los varones. En cuatro de los cinco países analizados como receptores abarcaba a $50 \%$ de los desplazamientos o más, inclusive. ${ }^{14}$ Los casos que más llaman la atención son los de Costa Rica, por el alto volumen de la migración, y el de Guatemala, pues allí las mujeres superaban $60 \%$ de los individuos nacidos en otro país centroaméricano. Debido a la carencia de información de la misma calidad para los migrantes temporales, no es posible determinar si esta misma característica es aplicable a todo el conjunto de la población, pero, solamente en este segmento de la población analizada, el perfil femenino de la migración señala una característica de apreciable importancia.

En suma, la composición por sexo de este grupo de población revela la posible relación entre la incorporación creciente de las mujeres al mercado laboral y su significativa presencia dentro de los circuitos de la migración intrarregional. En todos los países se registra la presencia de mujeres nacidas en

\section{Cuadro 2}

\section{Población censada nacida en otro país centroamericano, según país de} residencia y género

\begin{tabular}{|c|c|c|c|c|c|c|c|c|c|c|}
\hline \multirow{3}{*}{$\begin{array}{c}\text { País de } \\
\text { nacimiento }\end{array}$} & \multicolumn{10}{|c|}{ País de residencia y género } \\
\hline & \multicolumn{2}{|c|}{ Belice } & \multicolumn{2}{|c|}{ Costa Rica } & \multicolumn{2}{|c|}{ El Salvador } & \multicolumn{2}{|c|}{ Guatemala } & \multicolumn{2}{|c|}{ Nicaragua } \\
\hline & Hombres & Mujeres & Hombres & Mujeres & Hombres & Mujeres & Hombres & Mujeres & Mujeres & Hombres \\
\hline Belice & & & 63 & 41 & & & 255 & 273 & & \\
\hline Costa Rica & & & & & 415 & 441 & 319 & 418 & 2277 & 2450 \\
\hline E1 Salvador & 3117 & 2541 & 4000 & 4714 & & & 4981 & 9534 & 1200 & 936 \\
\hline Guatemala & 5472 & 5224 & 1033 & 963 & 2044 & 2480 & & & 459 & 441 \\
\hline Honduras & 1280 & 1057 & 1286 & 1660 & 3774 & 4892 & 1785 & 2849 & 4607 & 4866 \\
\hline Nicaragua & & & 113072 & 113302 & 969 & 1170 & 1641 & 1980 & & \\
\hline Panamá & & & 5440 & 4830 & 144 & 164 & & & 170 & 181 \\
\hline $\begin{array}{c}\text { TOTAL } \\
(\%)\end{array}$ & $\begin{array}{r}9869 \\
(52.8)\end{array}$ & $\begin{array}{r}8822 \\
(47.2)\end{array}$ & $\begin{array}{r}124894 \\
(49.9)\end{array}$ & \begin{tabular}{r|}
125510 \\
$(50.1)$
\end{tabular} & $\begin{array}{r}7346 \\
(44.5)\end{array}$ & $\begin{array}{r}9147 \\
(55.5)\end{array}$ & $\begin{array}{r}8981 \\
(37.4)\end{array}$ & $\begin{array}{l}15054 \\
(62.7)\end{array}$ & $\begin{array}{r}8713 \\
(49.5)\end{array}$ & $\begin{array}{r}8874 \\
(50.5)\end{array}$ \\
\hline
\end{tabular}

Fuente: Con base en información de Censos de Población, Base de Datos de INMILA. 
otro territorio centroamericano; en términos absolutos, su presencia es contundente en Costa Rica como resultado de la inmigración de mujeres nicaragüenses; aunque en proporciones menores, en otros países la presencia de mujeres es mucho más importante en términos relativos que la de los varones, al menos así parece ocurrir en Guatemala y El Salvador.

En otros términos, el desplazamiento de estos grupos señala una importante interacción entre países de origen y de destino. Así por ejemplo, las mujeres guatemaltecas tienden a orientarse más a Belice y a El Salvador; las salvadoreñas en primer lugar a Guatemala y a Costa Rica como segundo destino de la región. Las mujeres hondureñas han definido dos destinos principales: El Salvador y Nicaragua, y en segundo lugar, Guatemala. Finalmente, como se había señalado, Costa Rica es el destino principal de las mujeres nicaragüenses, quienes también tienen presencia en Guatemala. Costa Rica también recibe a mujeres panameñas. Como se apuntó, en República Dominicana también se visibiliza un crecimiento de la inmigración de mujeres haitianas junto con sus pares varones que emigran a las plantaciones azucareras o a otras actividades.

Esa configuración de flujos concuerda también con la modalidad transfronteriza de los desplazamientos. Es decir, los movimientos más importantes se producen entre países vecinos, quizás en virtud de que la migración se realiza esencialmente como un movimiento en el cual se privilegian puntos de destino de acceso relativamente fácil por tierra, donde tanto la distancia como el costo son variables importantes en la decisión de emigrar.

Ese factor no señala de ninguna manera un elemento de diferenciación por sexo, por cuanto los mismos destinos tienen igual importancia para mujeres y varones. No obstante, una cuestión que se debe valorar es la posible subrepresentación de características de género dentro de la estadística, en especial por el subregistro de jornaleros agrícolas y otros trabajadores temporales. Eso último suponiendo que, dentro de este subgrupo, la participación de mujeres sea baja, cosa que también requiere de constatación empírica, pues en algunas actividades de recolección la fuerza de trabajo de las mujeres resulta ser clave. Por las características de la información, este tema escapa de las posibilidades de este análisis, pero requiere que sea refrendado como problema de investigación en futuras investigaciones.

Otra característica que define a esa población inmigrante es la de sus bajos niveles de escolaridad. Casi una quinta parte de la población económicamente activa ligada a la migración no posee estudios, mientras que menos de $25 \%$ logró completar apenas la educación primaria. Es decir, que casi la mitad de los inmigrantes se ubica en niveles de estudios con sexto grado o debajo de él. Es importante reconocer que en casi todos los países se presenta una estrecha relación entre la incorporación de jóvenes y adolescentes dentro de las estrategias migratorias y el abandono del sistema escolar. ${ }^{15} \mathrm{La}$ mayoría de los jóvenes hombres y mujeres, entre los 12 y 19 años, no completó siquiera la instrucción primaria. Un ejemplo al respecto es que $42.5 \%$ de los nicaragüenses entre los 12 y 19 años, en Costa Rica, experimentaba esa situación. También es importante destacar que principalmente, en el caso de Costa Rica, conforme mejoran los niveles de escolaridad también aumenta la presencia de mujeres en cada rango escolar; mientras que en los demás países los bajos niveles de escolaridad no establecen diferencias claras entre sexos. Sin embargo, el perfil de escolaridad más alto entre las mujeres nicaragüenses se repite tanto en Guatemala como en $\mathrm{El}$ Salvador, lo que está evidenciando que desde ese país 
se está produciendo una significativa fuga de recursos humanos, y que las mujeres nicaragüenses, pese a sus niveles de instrucción, no logran integrarse al mercado laboral en condiciones que les permitan evadir el riesgo de la migración en su propio país.

Aunque no se dispone de otros datos, es muy posible que la migración logre explicar ciertas particularidades de la inserción de las mujeres en los mercados laborales. En el caso de Nicaragua, las mujeres, aun con más años de estudio que los varones, son las que están emigrando en mayor magnitud. Esa situación señala una clara diferenciación por sexo en relación con las oportunidades laborales y de ingreso en el país de origen y un creciente recargo sobre las mujeres, dentro de los hogares, de la obligación de emigrar. Aunque el nivel educativo de las mujeres tienda a ser mejor, la probabilidad de convertirse en migrante no disminuye; pero esa situación no necesariamente se traduce en la obtención de mejores oportunidades laborales en los países anfitriones. Esa misma condición tiende a repetirse en el caso de las emigraciones hacia los Estados Unidos, donde el tipo de migración exige a las mujeres tanto como a los varones de mayores niveles de instrucción, sobre todo para enfrentar las barreras idiomáticas, culturales y migratorias. En otras palabras, de nuevo puede constatarse que las migraciones están ocasionando a los países de origen de los migrantes la salida de una buena parte de sus recursos más calificados, sin que se haya probado que esa “inversión" les esté proporcionando a tales países el retorno de los recursos y del capital necesario para superar la pobreza y enfrentar los diversos retos de desarrollo social.

Es necesario, por otra parte, mejorar los sistemas de información relativos a la inserción de los trabajadores, hombres y mujeres, en las diversas ramas de la actividad productiva en los países de recep- ción. Tanto los datos censales como los procedentes de otras fuentes, como encuestas de hogares y de empleo, en la mayor parte de los países, no ofrecen información desagregada sobre la situación laboral de los inmigrantes; la problemática específica de los trabajadores temporales prácticamente se encuentra invisibilizada en la mayor parte de los estudios e informes sobre la materia y, por otra parte, el tipo de análisis no toma en cuenta la movilidad y otras particularidades de los segmentos de mercado donde se insertan estos grupos.

\section{Conclusiones}

En este trabajo hemos indagado en torno a las diversas expresiones que asume la territorialidad social en el contexto de la planetarización social y desde la dinámica de las migraciones. Se ha partido de la idea de que la vinculación entre espacios de origen y de destino, a través de las migraciones, hoy en día es una dinámica cada vez más intensa entre países y poblaciones vecinas, dentro de un proceso de reconstrucción de la regionalidad ístmica de las siete sociedades nacionales que conforman Centroamérica. También desde un punto de vista teórico el trabajo se emprendió por el interés en analizar el peso que tiene la constitución de redes sociales y el establecimiento de diversas formas de contacto entre regiones transfronterizas, y nuevos territorios en la formación de nuevas expresiones de regionalidad socioterritorial.

En ese sentido, hemos señalado que la emigración/inmigración es un solo fenómeno. En su producción subyacen factores estructurales que son propios de los territorios de salida como de los sitios anfitriones. Esas causas estructurales, como se ha demostrado, tienen origen en las características de los sistemas productivos, y específicamente en el em- 
pleo, pero también son la consecuencia de condiciones históricas, culturales y geográficas que incentivan el desarrollo de una interdependencia variada y constante.

Asimismo, la dinámica migratoria produce modificaciones importantes tanto en las comunidades de origen como en las de destino. Esas modificaciones se pueden examinar también en la actividad socioproductiva, las dinámicas familiares y la vida societal y cultural en general (dimensión organizativa, comportamientos colectivos y relaciones sociales). La migración también incentiva otras variaciones en los mecanismos de relación entre comunidades de origen y comunidades receptoras; y ello produce una conexión e interdependencia territorial también altamente dinámica: el desarrollo de un territorio o región se vuelve dependiente del otro y viceversa; en la medida en que entran en juego factores relacionados con la demanda y oferta de trabajo, redes de apoyo, remesas familiares, abastecimiento, consumo e inversión, y esos procesos no son fácilmente revertibles. Todo lo contrario, emergen como la manifestación de la regionalización de sistemas productivos, la transnacionalización del empleo y supranacionalidad de las redes sociales y también de las culturas locales.

El contacto de los emigrantes con sus comunidades de origen no sólo se produce a través del envío de remesas de dinero obtenido como fruto de su trabajo, sino a través de una serie de otras transferencias, tanto materiales como simbólicas, que se constituyen en mecanismos funcionales para la reproducción social de su grupo y el mantenimiento de su identidad y cultura. De esas transferencias se deriva la formación de un patrimonio de experiencias y conocimientos que servirían de apoyo al desarrollo de nuevas migraciones.

En relación con la problemática de las fronteras se ha señalado que éstas experimentan un cambio en la naturaleza de su función territorial y geopolítica.
Es decir, recobran su naturaleza como espacios que albergan un conjunto de dinámicas que a) revitalizan los viejos lazos y formas de comunidad que quedaron rotos por la intervención colonial y la formación de los territorios nacionales; b) establecen nuevos circuitos transfronterizos de intercambio de bienes y de personas; c) le otorgan a los territorios fronterizos locales una nueva función, ya no como espacios de separación sino de integración y de cooperación; d) propician el desarrollo de un sentido de identidad "transnacional" entre los pobladores y actores locales que entra en fricción con el tratamiento de las relaciones interestatales desde las viejas doctrinas de la seguridad y el control territorial.

En relación con el tema de las migraciones, implica que hablar hoy en día de la globalización en Centroamérica, obliga a ubicar las migraciones como uno de los escenarios más importantes, quizás el más importante desde el punto de vista social, que ilustra las nuevas formas de interdependencia que se establecen entre los territorios (países y localidades) de la región con su medio externo transnacional. Hasta la década de los setenta este fenómeno se concentraba en las migraciones internas y las migraciones transfronterizas entre países vecinos, hacia zonas de frontera agrícola o zonas de producción para la agroexportación, con una pequeña presencia de inmigraciones hacia zonas urbanas. En los años ochenta, las migraciones forzadas por la violencia armada comienzan a combinarse con los primeros indicios de la migración extrarregional, principalmente de salvadoreños y nicaragüenses hacia Estados Unidos.

En los años ochenta y noventa, el proceso de ajuste estructural se convierte en el factor que en la base material de la economía política centroamericana crea las condiciones para la organización de nuevos flujos laborales. La emigración hacia los Estados Unidos desplaza en importancia a las mi- 
graciones intercentroamericanas hasta mediados de la década de los años noventa. Pero a partir de la segunda mitad de la década de los noventa, se observa un fenómeno caracterizado por el resurgimiento de las migraciones transfronterizas, aunque se carece de información y de un mejor conocimiento para documentar este fenómeno de mejor manera.

Este fenómeno evidencia una de las nuevas formas de exclusión social, en una dimensión diferente a los antagonismos socioeconómicos del modelo anterior. En efecto, se trata de una situación estructural que padecen amplias masas de población, cuyas formas de privación y exclusión se trasladan de los escenarios de los estados nacionales (donde se acunaron los conflictos armados hasta los años ochenta) hacia la arena regional y trasnacional. Gran parte de ese conjunto de población es privada además del reconocimiento de sus derechos a la ciudadanía, no digamos de la ciudadanía política de masas de indocumentados que traspasan las fronteras, sino de la ciudadanía económica y la social.

También el fenómeno pone en evidencia una nueva segmentación de los mercados laborales, asociada a la migración, que es tanto una segmentación social como étnica, con sus variantes extremas relacionadas con la discriminación por género y edad.

Estos temas constituyen, de cara a las expectativas que genera la globalización en Centroamérica, uno de los principales desafíos para pensar a Centroamérica como región y para encarar los desa-

\section{Cuadro 3}

Migración internacional en Centroamérica

\begin{tabular}{|c|c|c|c|c|c|c|c|c|c|c|}
\hline \multirow[b]{2}{*}{$\begin{array}{l}\text { País de } \\
\text { residencia }\end{array}$} & \multirow[b]{2}{*}{ Año } & \multirow[b]{2}{*}{$\begin{array}{c}\text { Población } \\
\text { total }\end{array}$} & \multirow{2}{*}{$\begin{array}{c}\text { Total } \\
\text { nacidos } \\
\text { en } \\
\text { extranjero }\end{array}$} & \multicolumn{7}{|c|}{ País de Nacimiento } \\
\hline & & & & Belice & CR & $\begin{array}{c}\text { El } \\
\text { Salvador }\end{array}$ & Guatemala & Nicaragua & Panamá & Honduras \\
\hline Belice* $^{*}$ & 1991 & 184722 & 30834 & & & 5658 & 10696 & & & 2337 \\
\hline \multirow{4}{*}{$\begin{array}{c}\text { Costa } \\
\text { Rica }\end{array}$} & 1963 & 1336274 & 34981 & ----- & & $-\cdots$ & ----- & 18368 & 3232 & $-\cdots$ \\
\hline & 1973 & 1871780 & 46077 & ----- & & 1385 & 707 & 23331 & 4197 & 996 \\
\hline & 1984 & 2416809 & 88954 & 246 & & 8748 & 1431 & 45918 & 4794 & 1574 \\
\hline & 2000 & 3810179 & 296461 & 104 & & 8714 & 1996 & 226374 & 10270 & 2946 \\
\hline \multirow{2}{*}{$\begin{array}{c}\text { El } \\
\text { Salvador }\end{array}$} & 1971 & 3554648 & 22432 & ----- & 141 & & 3413 & 784 & 5 & 14290 \\
\hline & 1992 & 5118599 & 26279 & 134 & 212 & & 4524 & 2139 & 308 & 8666 \\
\hline \multirow{3}{*}{ Guatemala } & 1973 & 5160221 & 37454 & 965 & 805 & 14052 & & 1098 & 217 & 6231 \\
\hline & 1981 & 6054227 & 40220 & 832 & 733 & 16805 & & 2133 & 235 & 5326 \\
\hline & 1994 & 8331874 & 41352 & 528 & 737 & 14425 & & 3621 & 245 & 4634 \\
\hline \multirow{2}{*}{ Nicaragua } & 1971 & 1877952 & 21174 & ----- & 4693 & 2210 & 451 & & 590 & 6919 \\
\hline & 1995 & 4357099 & 26043 & 48 & 4727 & 2136 & 900 & & 351 & 9473 \\
\hline \multirow{3}{*}{ Panamá } & 1970 & 1352344 & 57275 & ------ & 3825 & ------ & $\begin{array}{l}----- \\
-\end{array}$ & 2582 & & ------ \\
\hline & 1980 & 1824796 & 47722 & 135 & 3359 & 1791 & 317 & 3128 & & 464 \\
\hline & 1990 & 2329329 & 61394 & 63 & 3828 & 2340 & 367 & 4447 & & 623 \\
\hline \multirow{3}{*}{ Honduras } & 1961 & 1884765 & 51204 & ------ & 294 & 38002 & 4497 & 3553 & 159 & \\
\hline & 1974 & 2656948 & -------- & ------- & ------ & -------- & ------------ & |------ & -------- & \\
\hline & 1988 & 4248561 & 34387 & ------- & ----- & ------- & -------------- & ------- & ------- & \\
\hline
\end{tabular}

* No se tuvo acceso a información estadística anterior ni posterior. El total de otros centroamericanos, aparte de los países indicados en el cuadro, fue 465 , la mayoría de ellos nicaragüenses.

Fuente: Base de datos IMILA. Boletín Demográfico N. 65. Enero 2000. CELADE. INEC, Costa Rica, 2001; y Oficina Central de Estadística de Belice, 1999. 
Mapa: Migraciones internacionales en Centroamérica (1990-2000)

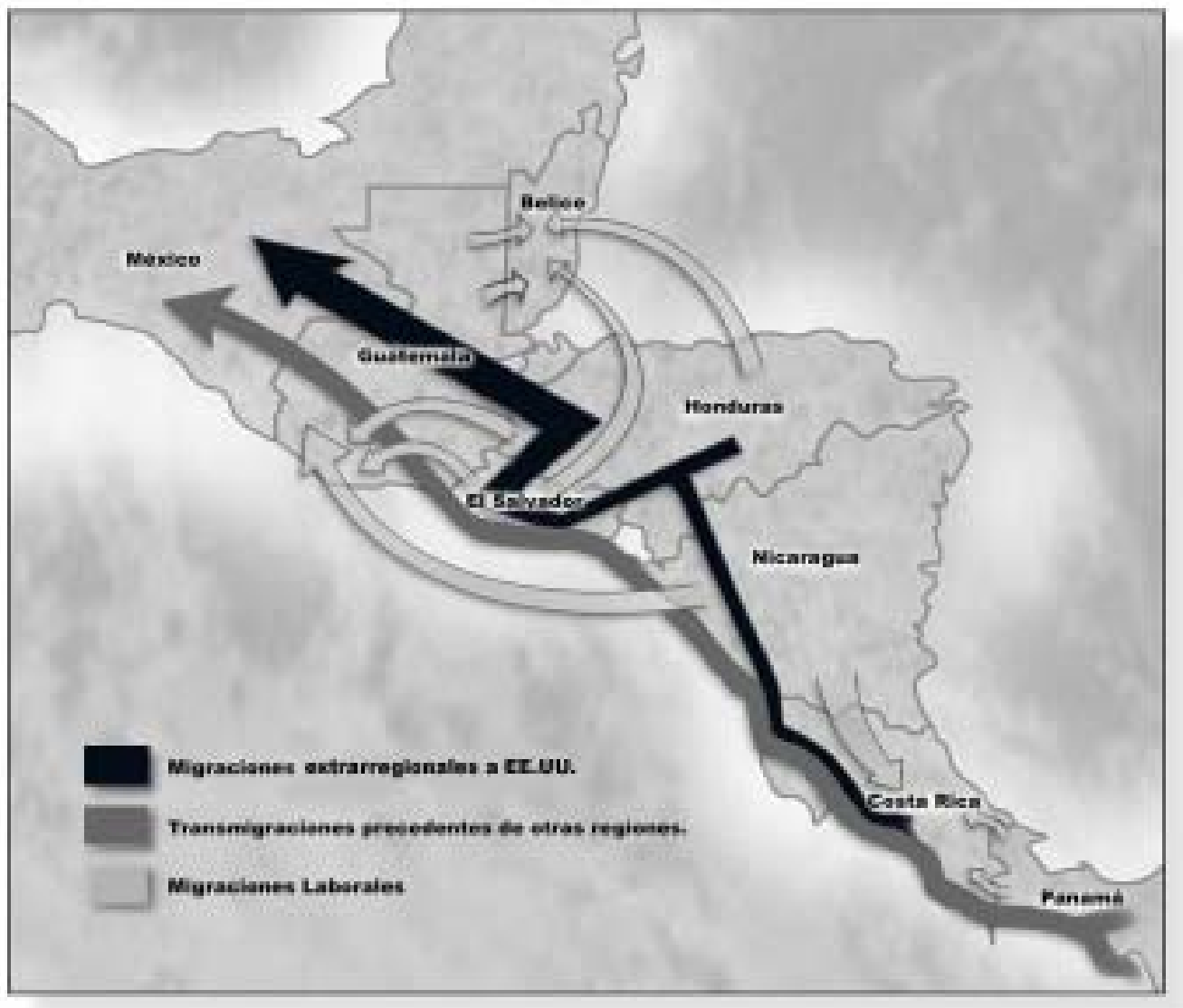


fíos de una agenda social largamente postergada por los Estados y por los principales actores que usufructuan las estructuras de poder.

\section{Notas}

${ }^{1}$ Este autor opone el concepto de "lugar" al de "no lugar" y aclara que "si un lugar puede definirse como lugar de identidad, relacional e histórico, un espacio que no puede definirse ni como espacio de identidad ni como relacional ni como histórico, definirá un no lugar"' (83).

${ }^{2}$ Una imagen del inmigrante procede de un imaginario social impuesto por la publicidad y los medios de comunicación, y otra, más cruda, corresponde a sujetos que sobreviven, en su mayor parte, en el envés de las vallas publicitarias y debajo de los límites de la subsistencia.

${ }^{3}$ A propósito, la antropóloga mexicana Ana Rosas Mantecón (1996), al analizar el papel del cine en la construcción de imaginarios urbanos y la migración, escribió: "la persistencia del estereotipo del migrante ha coadyuvado a la discriminación de ese otro, y a la atribución de falsas responsabilidades en las explicaciones de los males de la ciudad" (131).

${ }^{4}$ Un profundo análisis sobre la relación entre la transformación productiva y mercados de trabajo en Centroamérica se encuentra en Pérez Sáinz (1996).

${ }^{5}$ James Scott (1995) señala al respecto que "aun siendo tan importante la acción regional, es dudoso que la competencia libre entre regiones pueda sustituir a las medidas de intervención estatal y a una política económica y social integral" (73).

${ }^{6}$ Con frecuencia es una migración de varones, jornaleros agrícolas, que se dirigen a las fincas de producción de café, caña de azúcar, frutas de exportación y bananos; no obstante, en estos desplazamientos ha comenzado a ser creciente la presencia de mujeres (como acompañantes o como trabajadoras), así como la migración de núcleos familiares completos.

${ }^{7}$ No se disponía de información para la República Dominicana. ${ }^{8}$ Aunque pudieran ser consideradas como sinónimo, en este trabajo vamos a hablar específicamente de migraciones transfronterizas.

${ }^{9}$ Tampoco existe certeza sobre el número de centroamericanos que salió de sus países durante la guerra, pues aunque ACNUR estima que alrededor de dos millones de personas tuvieron que huir de sus países, solamente un porcentaje de esa población calificó bajo el estatus de refugiados. Muchos miles de personas salieron de sus países y permanecieron en calidad de indocumentados en territorios vecinos. Según Mármora (1996) entre uno y dos millones de refugiados salvadoreños, nicaragüenses y guatemaltecos estaban distribuidos en los distintos países centroamericanos al finalizar la década de los años ochenta. Hacia 1991 cerca de 700000 a 1100000 inmigrantes indocumentados residían en la región.

${ }^{10}$ No se logró captar ninguna base de información que proveyera un dato cierto sobre la estimación de inmigrantes haitianos en República Dominicana.

${ }^{11}$ Por otra parte, los sistemas de información migratoria de los países centroamericanos presentan una gran cantidad de limitaciones; no ha sido sino hasta el año 2001 que los gobiernos de la región han iniciado un esfuerzo para desarrollar un sistema con apoyo de la Organización Internacional para las Migraciones (OIM), pero dicha iniciativa todavía estaba en su fase de diseño e implementación inicial.

${ }^{12}$ Un detalle de algunos de estos movimientos para el período en estudio puede observarse en el cuadro 3 (IMILA) y en el mapa adjunto tomado de Castillo y Palma (1996) para el período de 1980 a 1994.

${ }^{13}$ Los colombianos pasaron de $1.89 \%$ del total de inmigrantes en Costa Rica en 1984 a constituir $2.0 \%$ en 2000; mientras que en toda la región resalta el incremento de las inmigraciones de personas de América del Sur y desde otros continentes.

${ }^{14}$ Debe tenerse cuidado a este respecto pues se trata de información para diferentes años, pues la aplicación de los censos se hizo con diferencias de hasta más de 10 años entre unos países y otros; por lo que no puede resultar pertinente obtener un promedio regional.

${ }^{15} \mathrm{La}$ inasistencia completa es un hecho casi generalizado entre los niños y niñas descendientes de haitianos en República Dominicana.

\section{Bibliografía}

Adams, Richard, 1981, "The dinamics of Societal Diversity: Notes from Nicaragua for a Sociology of Survival", American Ethnologist, Vol. 8, Núm. 1.

Alger, Chadwick, 1988, "Perceiving, analysing and coping with the local-global nexus", International Social Science Journal, Vol. XL, Núm. 3. 
Anderson, Benedict, 1983, Imagined Communities: Reflections on the origins and spread of nationalism, Verso, New York.

Arizpe, L. y Gortari, L. de, 1990, Repensar la Nación: Fronteras, etniasy soberanía, CIESAS, Cuadernos de la Casa Chata 174, México. Arndt, Michael, 1995, "Repercusiones regionales de los Nuevos Bloques Económicos: El Mercado Común Europeo y la situación de los Nuevos Estados Federados", en Jesús Arroyo Alexandre, Regiones en Transición. Ensayos sobre integración regional en Alemania del Este y en el Occidente de México, Universidad de Guadalajara, Guadalajara.

Augé, Marc, 1996, Los “no lugares”. Espacios del anonimato. Una antropología de la sobremodernidad, Gedisa, Barcelona.

Barber, Benjamin R., 1996, Jihad vs. McWorld. How Globalism and Tribalism are reshaping the world; Ballantine Books, Nueva York.

Basch, Linda, Glick Schiller y Szanton Blanc, 1994, Nations Unbound: Transnational projects, Postcolonial Predicaments, and Deterritorialized Nation-states, Gordon and Beach, Amsterdam.

Benko, Georges and Alain Lipietz, 1994, Las regiones que ganan. Distritosy redes. Los nuevosparadigmas de la geografía económica, Edicions Alfons el Magnánim, Valéncia.

Blanco, María Cristina, 1995, "El inmigrante como sujeto marginado. Claves interpretativas”, Juan Pedro Alvite (coord.), Racismo, antirracismo en inmigración, Gráficas Lizarra, Donostia.

Bolin, William, 1992, "The Transformation of South America's Borderlands", en Lawrence A. Herzog, Changing Boundaries in the Americas. New Perspectives on the U.S.-Mexican, Central American, and South American Borders, Center for U.S.-Mexican Studies. University of California, San Diego.

Borja, Jordi y Manuel Castells, 1997, Localy Global. La gestión de las ciudades en la era de la información, Taurus, Madrid.

Bovin, Phillippe, 1997, Las fronteras del istmo. Fronteras y sociedad entre el Sur de México y América Central, CIESAS - CFEMCA, México.

Casillas, Rodolfo, 1992, Los procesos migratorios centroamericanosy sus efectos regionales, en Cuadernos de FLACSO Núm. 1, FLACSO México, México.

Castillo Girón, Víctor Manuel, 1995, Solo Diosy el Norte. Migración a Estados Unidos y Desarrollo de una región en Jalisco, Universidad de Guadalajara, Guadalajara.

Castillo, Manuel Angel, 1994, "A preliminary analysis of emigration determinants in México, Central America and Northern South America and Caribbean", in International Migration, Vol. xxxII, Núm. 2, pp. 269-306.
—, 1995, "Las migraciones en la frontera sur de México", en Adrián Aguilar et. al., El desarrollo urbano de México a fines del siglo XX, INSEUR-NL - SOMEDE, México.

—, y Silvia Irene Palma, 1996, Emigración Internacional en Centroamérica: una revisión de tendencias e impactos, Debate 35, FLACSO, Guatemala.

Castles, Stephen, 1993, "La era inmigratoria. Cultura, incertidumbre y racismo", en Nueva Sociedad, 127: septiembreoctubre 1993.

Crahshaw, Martha Isabel y Abelardo Morales, 1998, Mijeres

Adolescentes y Migración entre Nicaragua y Costa Rica, (forcoming), Programa Mujeres Adolescentes y FLACso, San José y Managua. CSUCA, 1978, Estructura Demográfica y Migraciones Internas en Centroamérica, EDUCA, San José.

Chambers, Ian, 1994, Migrancy, culture, identity, Routledge, London.

Chinchilla, Norma y Nora Hamilton, 1991, "Central American Migration: A Framework for Analysis", Latin American Research Review, Vol. 26, Núm. 1, Winter 1991:75.

Derycke, P. H., edi. 1992, Espace et dynamiques territoriales, Económica, París.

Duchacek, Ivo, 1986, The Territorial Dimension of Politics, within, between and across boundaries, Westview, Boulder Co.

Fábregas P., Andrés, 1990, “Teoría y Práctica del Concepto de Frontera: El caso de México”, en Alfredo Buenrostro (Edit.), Fronteras en Iberoamérica ayery boy. Memorias del Congreso Internacional, Tomo I, Universidad Autónoma de Baja California, Tijuana.

Ferrer, Christian, 1993, "Los intrusos. Frontera y cicatriz", en Nueva Sociedad, 127: setiembre-octubre 1993.

Fonseca, Elizabeth, 1996, Centroamérica: Su Historia, FLACso/ EDUCA, San José.

Foucher, Michel, 1986, L" invention des frontieres, Fondation pour les Estudes de Defense Nationale, Collection les 7 epees, Documentation Francaise, Paris.

Friedmann, John, 1992, "Mass emigration, remittances and economic adjustment: the case of El Salvador in the 1980's", in Freeman, Richard and George Borges, eds., Inmigration and the Work Force: Economic consequences for the U.S. and Source Areas, University of Chicago Press, Illinois.

García Canclini, Néstor, 1991, Culturas híbridas. Estrategias para entrary salir de la modernidad, Editorial Grijalbo, México.

—, 1995, Consumidoresy Ciudadanos. Conflictos Multiculturales de la Globalización; Editorial Grijalbo, México. 
Glick-Schiller, Nina et al. 1992, Towards a Transnational Perspective on Migration: Race, Class, Ethnicity and Nationalism Reconsidered, New York Academy of Sciences, New York.

Gold, Steven J., 1998, Transnationalism: itspotential for understanding migration in a globally integrated world, Lansing, Department of Sociology, Michigan State University.

_, 1997, "Difuminando fronteras: construcción de la comunidad transnacional en el proceso migratorio MéxicoEstados Unidos", en Macías Gamboa and Herrera Lima, Migración Laboral Internacional, Universidad de Puebla, Puebla.

Gottman, Jean, 1973, The significance territory, University Press of Virginia, Charlottesville.

Granados, Carlos, 1985, "Hacia una definición de Centroamérica", en Anuario de Estudios Centroamericanos, Vol. 11, Fascículo 1, San José, pp. 59-78.

Harvey, D. Scott, 1989, The condition of post-modernity, Oxford, Basil Blackwell.

Hasemann, G. y Gloria Lara Pinto, 1994, "La Zona Central: Regionalismo e Interacción", en Carmack, Robert, Historia General de Centroamérica. Historia Antigua, tomo I, FLAcso San José, Costa Rica.

Herrera Lima, Fernando, 1997, "Las familias transnacionales: una institución relevante en los procesos de transmigración", en Herrera Lima y Macías Gamboa, Migración laboral internacional. Herzog, Laurence, ed., 1992, Changing Boundaries in the Americas. New Perspectives on the U.S.-Mexican, Central American, and South American Borders, Center for U.S.-Mexican Studies, University of California, San Diego.

Kristof, K. D., 1959, "The Nature of Frontiers and Boundaries", Annals of the Association of American Geographers, 49 (Sept.): 269-82.

Lungo, Mario, 1997, Migración Internacionaly Desarrollo, tomos I y II, Fundación Nacional para el Desarrollo, San Salvador.

Mantecón, Ana Rosas, 1996, "La ciudad de los migrantes: El cine y la construcción de los imaginarios urbanos", en Perfiles Lationoamericanos, Año 5, Núm. 9, diciembre.

Mármora, Lelio, 1997, Las politicas de migraciones internacionales, Alianza Editorial, Buenos Aires.

Mattai, Horst, 1990, "El Hombre y sus Fronteras: Una visión filosófica”, en Alfredo Buenrostro (Ed.), Fronteras en Iberoamérica ayery boy. Memoria del Congreso Internacional, tomo I, Universidad Autónoma de Baja California, Tijuana.

Melucci, Alberto, 2001, Vivencia y convivencia. Teoría social para una era de la información, Editorial Trotta, Madrid.
Morales, Abelardo, 1995, Oficios de Paz y Posguerra en Centroamérica, Flacso San José, Costa Rica.

— ,1997a, Los territorios del Cuajipal. Frontera y Sociedad entre Nicaragua y Costa Rica, FLACso San José, Costa Rica.

- 1997b, Multilateralismo Social. Las ONGsy la cooperación externa en la transición del conflicto bélico y la crisis a la construcción regional de Centroamérica, Universidad Nacional de Heredia, Costa Rica.

—, comp., 1997c, Las fronteras desbordadas, Cuaderno de Ciencias Sociales, Núm. 104, FLAcso San José, Costa Rica.

—, y Martha I. Cranshaw, 1997, Regionalismo emergente: Redes de la sociedad civil e integración en Centroamérica, Ibid Dinamarca/FLACSO San José, Costa Rica.

Nye, Joseph Jr., 1990, “The Changing Nature of World Politics", Political Science Quarterly, No. 105, Summer.

Ohmae, Kenochi, 1990, The Borderless World. Power and Strategy in the Interlinked Economy, Harper Collins Publisher.

Papail, Jean y Jesús Arroyo Alexandre, 1996, Migración mexicana a Estados Unidos y desarrollo regional en Jalisco, Universidad de Guadalajara, Guadalajara.

Pérez-Sáinz, Juan Pablo, 1997, De la finca a la maquila. Modernización capitalista y trabajo en Centroamérica, FLACSO San José, Costa Rica. Pinto Coelho, Pedro, 1992, Fronteiras na Amazonia: Um Espacio Integrado. IPRI. Brasilia.

Portes, Alejandro, 1996, "Transnational Communities; their emerging and significance in the Contemprary World System", Working Papers Series, Núm. 16, (Baltimore, Department of Sociology, The John Hopkings University).

Pries, Ludger, 1997, "Migración laboral internacional y espacios sociales transnacionales: bosquejo teórico-empírico", Macías Gamboa y Herrera Lima, Migración laboral internacional, Universidad de Puebla, Puebla.

Roch, Isolde, 1995, "El significado de la frontera germanopolaca para Europa”, en Jesús Arroyo Alexandre, comp., Regiones en Transición: Ensayos sobre integración regional en Alemania del Estey en el Occidente de México, Universidad de Guadalajara, Guadalajara. Sassen, Saskia, 1994, Cities in the World Economy, Pine Forge Press, Thousand Oaks, Ca.

—, 1991, The Global City. New York, London, Tokio, Princeton University Press, Princeton, N.J.

—, 1997, The Mobility of Labor and Capital. A study in International Investment and L abor Flow, University Press, Cambridge.

Scott, James, 1995, "Tesis sobre el contexto supranacional del activismo regional; posibles consecuenicias en los nuevos estados de la República Federal de Alemania", en Jesús Arroyo 
Alexandre, Regiones en Transición. Ensayos sobre integración regional en Alemania del Este y en el Occidente de México, Universidad de Guadalajara, Guadalajara.

Simmons, Alan, 1995, International migration, Refugee Flows and Human Rights in North America: The impact of Free Trade Agreement and Restructuring, Center for Migration Studies, Staten Island, New York.

Taylor, Peter, 1994, Geografía Política. Economía-Mundo, EstadoNación y Localidad, Trama Editorial, Madrid.
Tilly, Charles, 1990, "Transplanted Networks", in Virginia Yans-McLaughlin (ed.) Inmigration Reconsidered: History, Sociology and Politics, Oxford University Press, New York.

Vanneph, Alain, 1997, "Frontera Norte: de las redes a la región transfronteriza", Philippe Bovin (coord.), Las Fronteras del Istmo. Verduzco, Basilio, 1995, "De la Investigación Científica al crecimiento regional sustentable: innovación tecnológica, crecimiento económico y competencia internacional", en Jesús Arroyo Alexandre, op. cit. 